\title{
ANTROPOLOGIA, CULTURA E INDIVÍDUO: REFLEXÕES SOBRE IDENTIDADE
}

\author{
Dinamara Garcia Feldens ${ }^{1}$ \\ Luana Garcia Feldens Fusaro ${ }^{2}$ \\ Lucas de oliveira carvalho ${ }^{3}$
}

\section{RESUMO}

O presente artigo tem o objetivo de fazer uma discussão em torno de alguns conceitos e de teóricos da Antropologia sobre identidade cultural. Para isto, aponta questões referentes à noção de sociedade, de cultura e de indivíduo. Estes elementos ajudam a compor o corpo daquilo que entendemos ser a noção de identidade cultural. Busca, também, fazer uma reflexão sobre a necessidade do estudo e da pesquisa dentro dessas temáticas, da constante reflexão sobre os métodos e ferramentas usados nas análises e do processo contínuo de transformação dos aspectos culturais e identitários.

Palavras-chave: Identidade cultural. Antropologia. Indivíduo. Sociedade.

\section{ANTHROPOLOGY, CULTURE AND THE INDIVIDUAL: REFLECTIONS ON IDENTITY}

\begin{abstract}
The present article aims to discuss around some concepts and theorists of Anthropology on cultural identity. Thereunto, it points out questions regarding the notion of society, culture and individual. These elements help to compose the body of what we consider the notion of cultural identity. It also seeks to reflect on the need for study and research within these themes, on constant reflection on the methods and tools used in the analysis and on the ongoing process of transformation of cultural and identity aspects.
\end{abstract}

Keywords: Cultural identity. Anthropology. Individual. Society.

\section{ANTROPOLOGÍA, CULTURA E INDIVIDUO: REFLEXIONES SOBRE IDENTIDAD}

\section{RESUMEN}

El presente artículo tiene el objetivo de hacer una discusión en torno a algunos conceptos y teóricos de la Antropología sobre identidad cultural. Para ello, se hace necesario apuntar cuestiones referentes a la noción de sociedad, de cultura y de individuo. Estos elementos ayudan a componer el cuerpo de lo que entendemos ser la noción de identidad cultural. También busca reflexionar sobre la necesidad del estudio y la investigación dentro de estas temáticas, de la constante reflexión sobre los métodos y herramientas usados en los análisis y el proceso continuo de transformación de los aspectos culturales e identitarios.

\footnotetext{
1 Doutora e pesquisadora em Educação, coordenadora do Grupo de Pesquisa Educação, Cultura e Subjetividades(GPECS) pela Universidade Federal de Sergipe (UFS) E-mail:<dfeldens@hotmail.com>.

${ }^{2}$ Mestranda do Programa de Pós-Graduação em Antropologia pela Universidade Federal de Sergipe (UFS) e bacharel em Comunicação Social - jornalismo pela Universidade Tiradentes. Participou de três projetos de iniciação científica, um deles pela Lei de Incentivo a Cultura (LIC), outro pela Fundação de Amparo a Pesquisa do Rio Grande do Sul (FAPERGS), e outro pelo Programa Institucional de Bolsas de Iniciação Científica. E-mail: <luafeldens@gmail.com>.

${ }_{3}^{3}$ Graduado em História (licenciatura) pela Universidade Tiradentes em 2010, membro do Grupo de Pesquisa: Educação, Cultura e Subjetividades (GPECS) Universidade Federal de Sergipe (UFS). E-mail: <lucas.historiando@gmail.com>.
} 
Palabras-clave: Identidad cultural. Antropología. Individuo. Sociedad.

\section{Introdução}

A Antropologia tem papel singular dentro dos estudos das Ciências Sociais. É a ciência que visa ao específico dentro do todo, que entende o indivíduo através de sua cultura, e a cultura a partir dos seus indivíduos, costumes, valores morais, crenças, ritos, relações de parentescos, hábitos alimentares, hierarquias, entre tantos outros elementos e variáveis que podem existir em torno do objeto que se pretende estudar.

Este texto propõe uma reflexão sobre alguns conceitos e teóricos da Antropologia, ao permear a noção de sociedade, de cultura e de indivíduo, considerando estes elementos essenciais na formação de uma noção de identidade cultural, uma questão que vem sendo discutida ao longo do tempo por pesquisadores sociais. Neste sentido, alguns temas e noções conceituais passam a compor o cenário do texto, dando embasamento para composição da discussão que segue.

Em essência, o argumento é o seguinte: as velhas identidades, que por tanto tempo estabilizaram o mundo social, estão em declínio, fazendo surgir novas identidades e fragmentando o indivíduo moderno, até aqui visto como um sujeito unificado (HALL, 2005, p.9).

Nesta revisão, a questão da identidade dentro de uma sociedade, de um grupo ou de um indivíduo pode ser percebida por diversos vieses. Não há uma regra científica ou uma metodologia única para definir o que constitui a identidade de alguém. Além disto, é através da cultura que uma parte significativa dos elementos identitários é formada.

O modo de ver o mundo, as apreciações de ordem moral e valorativa, os diferentes comportamentos sociais e mesmo as posturas corporais são assim produtos de uma herança cultural, ou seja, o resultado da alteração de uma determinada cultura (LARAIA, 2002, p.68).

Existem signos comuns e específicos, manifestações, costumes, valores, crenças que caracteriza um povo e, consequentemente, seus indivíduos. Estes elementos naturalmente transformam-se em referência para a identidade de quem o partilha, e até mesmo para quem os vê de fora, como observador. São essas tantas infinidades de aspectos e características dentro da cultura que oferecerão, além de ferramentas necessárias aos 
processos de referenciações identitárias aqui já citados, meios para que se possa distinguir uns dos outros, sejam indivíduos, comunidades ou grupos sociais, a partir da observação de suas peculiaridades e especificidades. Assim sendo, para que possamos compreender melhor as questões referentes à cultura e aos processos identitários, antes, é preciso trazer uma breve noção do que é cultura dentro do estudo da Antropologia, e o que é a Antropologia dentro do estudo das Ciências Sociais.

\section{O estudo antropológico e a cultura}

A Antropologia, como ciência, surge para suprir uma necessidade mais específica de estudo dentro das Ciências Sociais. Ao contrário da Sociologia, que faz análises mais gerais das relações na vida coletiva, a Antropologia busca entender o contexto do social a partir de seus indivíduos, hábitos e práticas culturais. "O que distingue a antropologia das outras ciências sociais é o ela incluir no seu campo, para as estudar cuidadosamente, Sociedades que não são a nossa sociedade" (BENEDICT, 1934, p.13). Não por acaso, os estudos antropológicos ganharam força e forma a partir de expedições para territórios distantes e de pouco acesso, transformando-se em uma ferramenta de conhecimento de outros povos e sociedades.

Em Inventando a Sociedade, Eric Wolf (2003) argumenta que, por muito tempo, sociólogos e antropólogos, embora com certa troca de referências, trataram o conceito de sociedade cada qual a seu modo, mantendo como noção condutora apenas a ideia de vida coletiva, como se todos os indivíduos que convivessem em um mesmo local compartilhassem das mesmas referências culturais. Entretanto, James George Frazer, um dos precursores dos estudos antropológicos, já afirmava, em 1908, que

[...] enquanto o nome Sociologia deve ser reservado para o estudo da sociedade humana no mais abrangente sentido das palavras, o nome Antropologia Social pode, com vantagem, ser restringido a um departamento particular daquele imenso campo de conhecimento (FRAZER, 1908, p. 47).

Neste sentido, são as particularidades e não as generalidades, que distinguem, definem e identificam povos e grupos sociais, e que indicam o objeto de interesse para o estudo das culturas humanas. Estas particularidades são identificadas a partir do olhar do antropólogo, que faz escolhas e define recortes que estabelecem os critérios para a construção essencial para a formulação do seu objeto de pesquisa. 
No livro Uma teoria científica da cultura, Malinowiski, um dos primeiros etnógrafos da antropologia expõe, em 1922, sua expectativa em relação à Antropologia como ciência. "[...] penso que se a antropologia puder contribuir para uma perspectiva mais científica de seu legítimo objeto, ou seja, a cultura, ela prestará um serviço inestimável às outras humanidades" (MALINOWKI, 1975, p. 15). Esta visão levou à construção do personagem do antropólogo enquanto uma autoridade dentro da etnografia, com técnicas capazes de observar e analisar seu objeto. Em Sobre a autoridade etnográfica, James Clifford (1998) traça um estudo sobre a formação da postura e da figura desta autoridade etnográfica, citando Malinowki como percussor da etnografia, com publicação de Os argonautas do Pacífico Ocidental, seguido dos trabalhos de vários outros autores, a exemplo de RadcliffeBrown e Margaret Mead.

Os argonautas são uma complexa narrativa, simultaneamente sobre a vida trobriandesa e sobre o trabalho etnográfico. Ela é arquetípica de conjunto de etnografias que com sucesso estabeleceu a validade científica da observação participativa (CLIFFORD, 1998, p. 27).

Esta nova forma de fazer pesquisa etnográfica trouxe consigo certo padrão de aplicabilidade, que determinava uma permanência mais longa do antropólogo nas aldeias, onde ele deveria aprender a se comunicar na língua dos nativos e compartilhar de suas práticas cotidianas. "O etnógrafo profissional era treinado nas mais modernas técnicas analíticas e modos de explicação científica" (CLIFFORD, 1998, p. 28).

Ao longo dos anos, o papel do antropólogo e os princípios da Antropologia foram se transformando e se reestabelecendo; mas, por um longo tempo, muitos pesquisadores alimentavam uma ideia de que o antropólogo tinha a missão de elucidar questões históricas a partir do estudo das sociedades selvagens, carregados de um olhar etnocêntrico. Frazer (1908) acreditava que o homem primitivo estava, para o civilizado, assim como a criança estava para o adulto e que, através do estudo das sociedades selvagens, era possível "elucidar a evolução social da humanidade em eras anteriores ao alvorecer da história (...)" (FRAZER, 1908, p. 49). Este pressuposto evolucionista guiou vários teóricos dos primeiros tempos da Antropologia. Edward Tylor (2005), em A ciência da Cultura deixa evidente, em diversos momentos, a perspectiva de superioridades das sociedades civilizadas em relação àquelas ditas selvagens ou primitivas. 
Vários pesquisadores posteriores reviram esta posição, e transformaram a postura do antropólogo diante do seu objeto de pesquisa. Ainda assim, no momento em que se analisam as culturas considerando a forma como elas se diferenciam, é natural que o antropólogo, ou qualquer outro pesquisador, crie parâmetros comparativos entre as sociedades, incluindo, sobretudo, suas próprias influências culturais.

Em Padrões de Cultura, Ruth Benedict (1934) dedica um capítulo somente para alertar o leitor, intitulado A nossa cegueira perante as outras culturas. Nele, a autora discorre sobre os perigos de o pesquisador deixar-se levar por um olhar etnocêntrico, geralmente, branco ocidental, que predominantemente pesa sob as demais culturas. Esta postura foi seguida por muitos antropólogos, podendo ser observada nas mais clássicas etnografias. O rompimento disto, que foi gradativamente ocorrendo nos trabalhos mais contemporâneos, levaram a Antropologia a discutir o relativismo cultural como método de observação nas pesquisas de campo, que caminha por uma linha onde o pesquisador se coloca mais compreensível, e menos analítico, perante o objeto.

Ruth Benedict (1934, p. 13) defende que

Interessa para o antropólogo a vasta gama de costumes que existem em culturas diferentes, e o seu objeto é compreender o modo como essas culturas se transformam e se diferenciam, as formas diferentes por que se exprimem, e a maneira como os costumes de quaisquer povos funcionam nas vidas dos indivíduos que os compõem.

Nota-se, a partir destas críticas, um esforço para construir um olhar mais relativizador sobre a cultura que, ao invés de taxar, enquadrar, comparar, compartimentar visões e conceitos muitas vezes distorcidos e viciados, agora tentava, ao menos, ser mais flexível diante dessas análises, buscando entender, de fato, como essas dinâmicas funcionam dentro do próprio contexto do objeto de estudo, reconhecendo, ali, suas particularidades. Em outras palavras, começa a existir um movimento que tenta entender a cultura de determinados indivíduos, grupos ou sociedades através dos contextos e realidades em que eles estão inseridos, e não a partir de conceitos ou preconceitos construídos como se o entendimento sobre a cultura de determinado objeto fosse fruto de uma abstração.

De qualquer maneira, a ideia de estudar uma sociedade, além da sua própria, conduziu toda a trajetória da Antropologia por muitos anos, no intuito de desvendar o 
desconhecido, entender as outras culturas, buscando semelhanças e diferenças. Malinowiski (1975, p. 14) já argumentava que,

[...] ao escreve a respeito da abordagem científica do estudo do Homem, o antropólogo tem uma tarefa que, embora talvez não seja fácil, é de alguma importância. É seu dever definir em que relação realmente se situa de um para outro, os vários ramos da Antropologia.

O contato com culturas desconhecidas produz estranhamentos naturais para o pesquisador, que carrega consigo todas as suas vivências, valores morais e culturais. Entretanto, perceber as diferenças culturais e enxergá-las de forma aberta, receptiva, é tão importante para o andamento produtivo de uma pesquisa etnográfica quanto ter um olhar crítico de si mesmo. Em Introdução à Obra de Marcel Mauss, Claude Lévi-Strauss (2003, p. 27) enfatiza que:

Toda sociedade diferente da nossa é objeto, todo grupo de nossa própria sociedade, diferente daquele ao qual pertencemos, é objeto, todo costume desse mesmo grupo, ao qual não aderimos, é objeto. Mas essa série ilimitada de objetos, que constitui o Objeto da etnografia, e que o sujeito deveria arrancar de si dolorosamente se a diversidade das práticas e dos costumes não o pusesse diante de um fracionamento operado de antemão, jamais a cicatrização histórica ou geográfica poderia fazê-lo esquecer (sob pena de aniquilar o resultado de seus esforços) que tais objetos procedem dele, e que a análise desses, conduzida da forma mais objetiva, não poderia deixar de reintegrá-los na subjetividade.

A busca do diferente e a perspectiva do outro levaram as práticas das expedições a terras distantes, à pesquisa de campo e ao método etnográfico dentro do estudo antropológico. Sobre suas impressões durante as expedições que realizou, Malinowski (1975, p. 47) alerta, aos demais pesquisadores, que "[...] algumas realidades que parecem estranhas à primeira vista são essencialmente aparentadas aos elementos culturais humanos verdadeiramente universais e fundamentais [...)".

Na concepção de Tylor (2005, p. 35), também considerado um dos fundadores da antropologia cultural, "a lista de todos os itens da vida geral de um povo representa aquele todo que chamamos sua cultura". Ao pensar a cultura de um povo, pode-se facilmente verificar que ela é constituída por diversos elementos e características que estão compondo sua história, seus hábitos, tradições, saberes e memórias, atravessados por elementos das 
práticas cotidianas, alimentares, econômicas, de produção, e suas extensões no campo social. Estes e outros infinitos elementos, específicos de cada comunidade, com aspectos coletivos e singulares, que caracterizam a cultura do homem e de uma sociedade.

Uma definição mais contemporânea do termo cultura, de Eliot (2011), está colocada a partir de três sentidos diferentes: na perspectiva do indivíduo, de um grupo ou classe, ou do conjunto da sociedade. A partir desta diferenciação é possível visualizar, de maneira mais clara, como estas três definições interagem e se influenciam. "[...] a cultura de um indivíduo é dependente da cultura de um grupo ou classe, e que a cultura de um grupo ou classe é dependente da cultura do conjunto da sociedade à qual pertence aquele grupo ou classe" (ELIOT, 2011, p. 23). Do conceito de Eliot (2011), portanto, é possível imaginar uma pirâmide invertida em que o conjunto da sociedade estaria no topo, atuando sob as características dos demais sentidos. O autor enfatiza, ainda, que o sentido geral ou antropológico da palavra cultura floresceu independentemente dos outros sentidos.

O que delineia as características marcadas em uma cultura é o que as diferem de outras. Como exemplo disto, podemos pensar que um hábito que é comum para várias comunidades ou sociedades pode passar despercebido aos olhos das pessoas, enquanto uma dança, uma cantoria, ou um artesanato, que só exista em um determinado povoado, costuma ser mais notado e, por consequência, acaba caracterizando a referência que se faz daquele local. Laraia (2002) enfatiza que a cultura condiciona a visão de mundo do homem.

O modo de ver o mundo, as aspirações de ordem moral e valorativa, os diferentes comportamentos sociais e mesmo as posturas corporais são assim produtos de uma herança cultural, ou seja, o resultado da operação de uma determinada cultura (LARAIA, 2002, p. 68).

A argumentação de Laraia (2002) pode ser mais facilmente percebida através das relações nas sociedades tradicionais e comunidades menores, considerando que, geralmente, estes povos compartilham de uma cultura mais unificada em suas tradições, hábitos e ritos. Nas sociedades modernas e nos cenários urbanos, a cultura está fragmentada de diversas formas, seja a partir das relações sociais, de classe econômica, ou dos espaços que cada indivíduo ocupa dentro da sua própria comunidade e cultura. Ainda assim, cada povo carrega consigo elementos diversos, que os identificam enquanto um grupo, ou mesmo uma nação.

\section{Outras perspectivas sobre a identidade cultural}


A importância do indivíduo no contexto do estudo antropologia social é ressaltada por Frazer (1908), quando insinua que o estudo focado de um indivíduo, embora não traga a amplitude de todo o contexto social em que ele está inserido, possibilita, ao pesquisador, ter uma dimensão deste contexto. Mesmo que cada pessoa tenha sua personalidade, gostos e opiniões, não é possível isolar o indivíduo do seu contexto, do meio em que ele pertence. Suas características são constituídas a partir de suas vivências, referenciais, ensinamentos, valores, crenças e tudo mais que constitui aquilo que ele entende como sua cultura.

Franz Boas, na introdução do livro Padrões de Cultura, de Ruth Benedict (1934), destaca que os antropólogos devem "compreender o indivíduo como um ser que vive na sua cultura; e a cultura, como vivida pelos seus indivíduos" (BENEDICT, 1934, p. 9). Ao longo do texto, a autora confirma esta visão, defendendo que

Interessa para o antropólogo a vasta gama de costumes que existem em culturas diferentes, e o seu objeto é compreender o modo como essas culturas se transformam e se diferenciam, as formas diferentes por que se exprimem, e a maneira como os costumes de quaisquer povos funcionam nas vidas dos indivíduos que os compõem (BENEDICT, 1934, p. 13).

Esta perspectiva também reforça a noção de que a identidade de um indivíduo, inevitavelmente, é composta por suas interações sociais e pelas sociedades das quais ele faz parte. "De que maneira, ao longo dos séculos, através de numerosas sociedades, se elaborou lentamente, não o senso do 'eu', mas a noção, o conceito que os homens das diversas épocas criaram a seu respeito?" (MAUSS, 2003, p. 371). A frase de Mauss, retirada do texto Uma categoria do espírito humano: a noção de pessoa, a noção do eu, embora ocorra em outro âmbito, reflete a percepção sobre o pesquisado, assim como cabe, também, ao próprio pesquisador.

Para uma compreensão mais ampla em relação ao indivíduo, outra questão importante é a noção de que tanto a cultura quanto as questões identitárias estão em constante mudança, criação e transformação. "Desde que o indivíduo vem ao mundo, os costumes do ambiente em que nasceu moldam suas experiências dos fatos e a sua conduta" (BENEDICT, 1934, p. 15). Naturalmente que estas referências, por não chegaram e se estabelecerem no indivíduo em um único momento, mas gradualmente ao longo de sua vida, estão sempre colocando-o em metamorfose. Além do que, as relações que ele mantém, as 
várias influências que recebe e as vivências que experimenta produzem, ainda, novos sentidos identitários e culturais. Stuart Hall (2005) também considera que a identidade é móvel, formada e transformada continuamente.

O sujeito assume identidades diferentes em diferentes momentos, identidades que não são unificadas ao redor do "eu" coerente. Dentro de nós há identidades contraditórias, empurrando em diferentes direções, de tal modo que nossas identificações estão sendo continuamente deslocadas (HALL, 2005, p. 13).

Por outra perspectiva, pode se perceber influência diretamente na construção da identidade de cada indivíduo, grupo ou sociedade, a partir dos ambientes e meios em que ele estabelece suas relações com outros indivíduos. No artigo Memória e Identidade Social, Michel Pollak (1992, p. 5) define que o sentimento de identidade

é o sentido da imagem de si, para si e para os outros. Isto é, a imagem que uma pessoa adquire ao longo da vida referente a ela própria, para acreditar na sua própria representação, mas também para ser percebida da maneira como quer ser percebida pelos outros.

O que o autor sugere, neste sentido, é que a identidade do sujeito também pode assumir múltiplas formas, ressaltando, por vezes, algumas características ou outras, a depender do contexto em que este sujeito está inserido, por exemplo, dentro das relações familiares, nas relações de trabalho, entre outros. As atividades e relações cotidianas nos condicionam a assumir posturas diversas, resgatando a ideia de que não somos compostos de uma identidade única, mas de múltiplas identidades, que constituem a forma como nos vemos e nos mostramos diante de cada espaço e de cada relação. Sobre estas relações sociais, Hall (2005, p. ) entende que "são caracterizadas pela 'diferença'; elas são atravessadas por diferentes divisões e antagonismos sociais que produzem uma variedade de diferentes 'posições de sujeitos' - isto é, identidades - para os indivíduos. "

\section{Considerações finais}

Estudar a cultura e os processos identitários correlatos exige boa compreensão da complexidade e do dinamismo característicos dessas áreas, pois os objetos analisados dentro desta seara, de alguma forma, sempre estarão em constante mutação ou transformação. 
Estes estados contínuos de transformação inevitavelmente se mostram vinculados aos contextos e realidades nas quais estão inseridos. Podem vir de processos internos, dentro dos próprios sistemas de cultura e, por isto, parecerem mais lentos, graduais, quase imperceptíveis. Também podem vir de processos externos, resultantes do contato de culturas diferentes, aparentando serem mais abruptos e ocasionando mudanças mais perceptíveis. De um jeito ou de outro, para quem pesquisa, é necessário agregar ferramentas capazes de acompanhar e entender todas essas flutuações inerentes à cultura e às identidades. Como bem afirma Roque de Barros Laraia (2002, p. 101),

[...] cada sistema cultural está sempre em mudança. Entender esta dinâmica é importante para atenuar o choque entre as gerações e evitar comportamentos preconceituosos. Da mesma forma que é fundamental para a humanidade a compreensão das diferenças entre povos de culturas diferentes, é necessário saber entender as diferenças que ocorrem dentro do mesmo sistema. Este é o único procedimento que prepara o homem para enfrentar serenamente este constante e admirável mundo novo do porvir.

Sendo assim, fazer uma reflexão sobre conceitos e teóricos que estão relacionados aos estudos sobre identidade e cultura é sempre uma tarefa complexa, pois a discussão em torno do tema envolve um emaranhado bastante vultoso de teorias e pensadores. Por isto mesmo, fazer este exercício reflexivo é um processo importante e necessário para clarear e enriquecer o debate. Além disto, também ajuda a reconhecer as armadilhas, os engessamentos e outros tantos fatores que podem nos prender nessa teia de conceitos, limitando e viciando o olhar sobre nosso foco.

Portanto, pensar a identidade cultural também é uma forma de existir para além de suas barreiras e, com isto, oferecer um elemento a mais, que possa contribuir com sua permanência ou transformação. Assim, as discussões, debates e estudos que circulam as identidades culturais não devem representar um fim em si mesmos. Ao contrário, devem ser a força pulsante capaz de alimentar e movimentar as engrenagens do pensamento e da reflexão sobre o tema, possibilitando, para além da maior capacidade de compreensão, a construção de arcabouços teóricos capazes de, ao máximo, acompanhar a fluidez e as transformações referentes à identidade e à cultura.

\section{REFERÊNCIAS}


BENEDICT, R. s/d. Padrões de Cultura. Lisboa: Edição "Livros do Brasil" (1a parte: pp. 13-70; 3a parte: pp. 247-304) (Apenas 1a parte. Disponível

em: $<$ https://pt.scribd.com/doc/200719437/RuthBenedict-Padroes-de-Cultura-1-pdf $>$.Acesso em: 10 jul. 2017.

ELIOT, T. S. "Notas para a definição de cultura”. Trad. Wolf, Eduardo. Ed. Realizações, São Paulo, 2011.

FRAZER, J. G. "O escopo da Antropologia Social”. In: Celso Castro (org.) Evolucionismo cultural. Rio de Janeiro: Jorge Zahar, 2005, pp. 101-127.Disponível em <http://sociofespsp.files.wordpress.com/2012/04/castro-c-evolucionismo-cultural.pdf >. Acesso em: 12 jul. 2017.

HALL, S. A identidade na pós-modernidade. 10a ed. DP\&A Editora. Rio de Janeiro, 2005.

LARAIA, R. B. Cultura: um conceito antropológico. 15a ed. Jorge Zahar Editor, Rio de Janeiro, 2002.

LÉVI-STRAUSS, C. Introdução à obra de Marcel Mauss. In: Marcel Mauss. Sociologia e Antropologia. São Paulo: Cosac \& Naify, 2003, pp. 11-46.Disponível em:

<http://www.4shared.com/office/02d59xc-/Sociologia e antropologia de M.html>. Acesso em: 15 jul. 2017.

MALINOWSKI, B. Uma teoria científica da cultura. Rio de Janeiro: Jorge Zahar Editores, 1975 (Cap. IV: pp. 43-48 / Caps. VII, VIII, IX e X: pp. 70-116).

MAUSS, M. Uma categoria do espírito humano: a noção de pessoa, a noção de eu. In: Sociologia e Antropologia. São Paulo: Cosac \& Naify, 2003, pp. 367-397. Disponível em <http://www.4shared.com/office/02d59xc-/Sociologia_e antropologia_de M.html>. Acesso em: 20 jul.2017.

POLLAK, M. Memória e Identidade Social. Trad. AUGRAS, Monique. Ed. Dória Rocha, Estudos Históricos, vol. 5, n.10, Rio de Janeiro, 1992.

TYLOR, E. "A ciência da cultura” In: Celso Castro (org.) Evolucionismo cultural. Rio de Janeiro: Jorge Zahar, 2005, pp. 67-99. Disponível em:

<http://sociofespsp.files.wordpress.com/2012/04/castro-c-evolucionismo-cultural.pdf>.

Acesso em: 22 jul. 2017.

RECEBIDO EM 18 DE AGOSTO DE 2017.

ACEITO EM 04 DE JULHO DE 2018. 